\title{
A lung mass: when the history helps the diagnosis
}

\author{
Jenny Bua, ${ }^{1}$ Federico Marchetti, ${ }^{1}$ Floriana Zennaro, ${ }^{2}$ Alessandro Ventura ${ }^{1}$ \\ 1Paediatrics Department, IRCSS Burlo Garofolo, Trieste, Italy; \\ ${ }^{2}$ Radiology Department, IRCSS Burlo Garofolo, Trieste, Italy
}

Correspondence to Dr Jenny Bua, jennybua@gmail.com

\section{DESCRIPTION}

A 7-years-old boy was referred to our hospital because of a large left upper para-mediastinal mass at x-rays (figure 1A) with the suspicion of lymphoma. He had no respiratory symptoms, auscultation was normal. High-resolution CT showed a large consolidated mass $(4 \times 3.5 \mathrm{~cm} \times 7.4 \mathrm{~cm})$ in the left upper pulmonary lobe, of lung origin as two

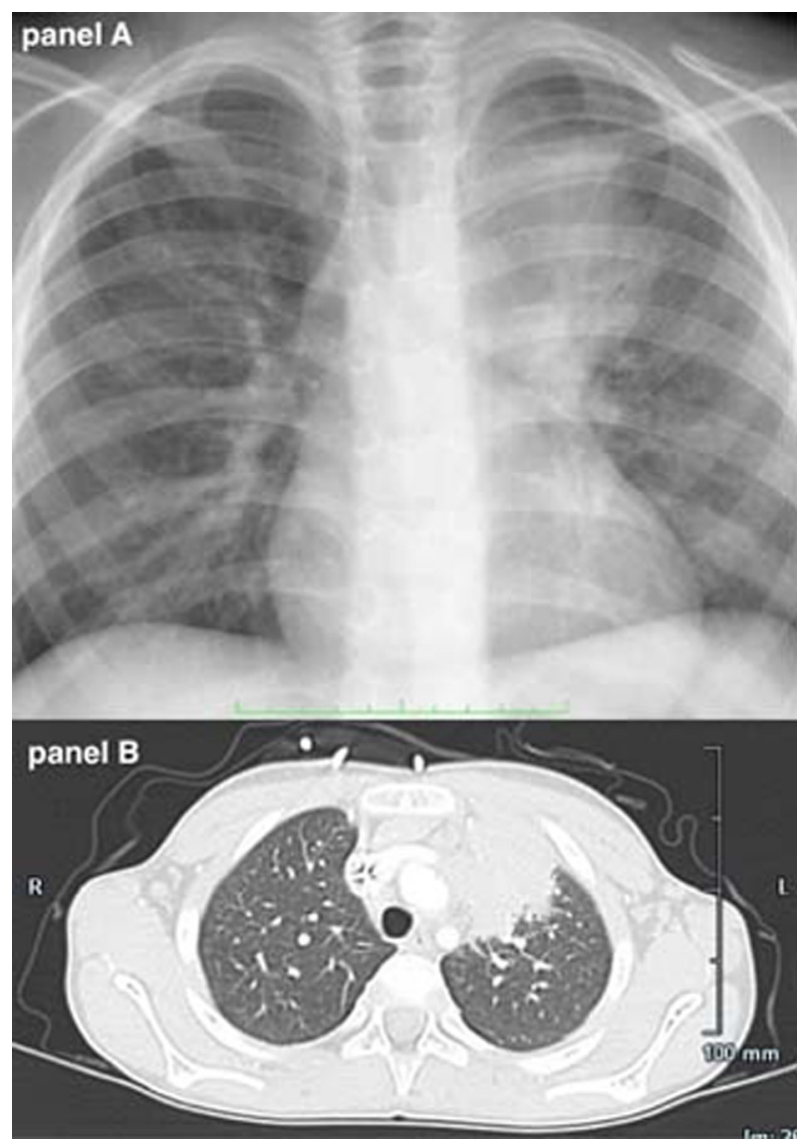

Figure 1 X-rays showing a left upper para-mediastinal mass (A). At high-resolution CT scan the same consolidated mass, with two bronchial branches in its context (B). bronchial branches (figure 1B). At admission the boy was on full anti-tuberculosis (TBC) treatment. Two months earlier he had had a third episode of suppurative laterocervical adenitis, with histological finding of granulomas, isolation of Staphylococcus aureus from culture and a weak positive Mantoux. The boy had received BCG at birth. A careful history revealed three episodes of laterocervical adenitis, all characterised by S.aureus isolation, and two episodes of osteomyelitis. The first episode of osteomyelitis involved the second finger of the left hand, while the second episode the third right toe. Recurrence of staphyloccocal adenitis, histological granulomatous aspect, no response to $\mathrm{TBC}$ treatment, osteomyelitis of small bones of hands and feet, male sex were all suggestive of chronic granulomatous disease (CGD). ${ }^{1}$ Nitroblue-tetrazolium test confirmed CGD. Given this diagnosis, our first hypothesis was pulmonary Aspergillosis as Aspergillus is the most frequently isolated organism in CGD patients. ${ }^{2} 3$ Aspergillus fumigatus was isolated from the hypopharyngeal culture confirming the diagnosis. Voriconazole was started leading to volumetric reduction of the aspergilloma which was later removed surgically. Histological examination showed fungal hyphae in the context of the removed mass.

Our patient has undergone a successful bone marrow transplantation and he is now on no treatment. Diagnosis of pulmonary aspergillosis remains difficult in that clinical manifestations are not specific and radiologic findings can be suggestive but none are pathognomonic. ${ }^{4}$ However, it should be always suspected in case of a consolidated mass in a CGD patient.

\section{Competing interests None.}

Patient consent Obtained.

\section{REFERENCES}

1. Seger RA. Modern management of chronic granulomatous disease. $\mathrm{Br} \mathrm{J}$ Haematol 2008; 140:255-66.

2. Martire B, Rondelli R, Soresina A, et al. Clinical features, long-term follow-up and outcome of a large cohort of patients with chronic granulomatous disease: an Italian multicenter study. Clin Immunol 2008;126:155-64.

3. Van den Berg JM, Van Koppen E, Ahlin A, et al. Chronic granulomatous disease: the European experience. PLoS One 2009;4:e5234.

4. Segal BH. Aspergillosis. N Eng/ J Med 2009;360:1870-84. 


\section{BMJ Case Reports}

This pdf has been created automatically from the final edited text and images.

Copyright 2011 BMJ Publishing Group. All rights reserved. For permission to reuse any of this content visit http://group.bmj.com/group/rights-licensing/permissions.

BMJ Case Report Fellows may re-use this article for personal use and teaching without any further permission.

Please cite this article as follows (you will need to access the article online to obtain the date of publication).

Bua J, Marchetti F, Zennaro F, Ventura A. A lung mass: when the history helps the diagnosis. BMJ Case Reports 2011;

10.1136/bcr.01.2011.3718, date of publication

Become a Fellow of BMJ Case Reports today and you can:

- Submit as many cases as you like

- Enjoy fast sympathetic peer review and rapid publication of accepted articles

- Access all the published articles

- Re-use any of the published material for personal use and teaching without further permission

For information on Institutional Fellowships contact consortiasales@bmjgroup.com

Visit casereports.bmj.com for more articles like this and to become a Fellow 